\title{
Loss of membranous VEGFR1 expression is associated with an adverse phenotype and shortened survival in breast cancer
}

\author{
PATRICK LEBOK $^{1}$, JULIA HUBER ${ }^{1}$, EIKE-CHRISTIAN BURANDT ${ }^{1}$, ANNETTE LEBEAU ${ }^{1}$, \\ ANDREAS HOLGER MARX ${ }^{1}$, LUIGI TERRACCIANO ${ }^{2}$, UWE HEILENKÖTTER ${ }^{3}$, FRITZ JÄNICKE ${ }^{4}$, \\ VOLKMAR MÜLLER ${ }^{4}$, PETER PALUCHOWSKI ${ }^{5}$, STEFAN GEIST $^{5}$, CHRISTIAN WILKE $^{6}$, \\ RONALD SIMON $^{1}$, GUIDO SAUTER $^{1}$ and ALEXANDER QUAAS ${ }^{7}$ \\ ${ }^{1}$ Institute of Pathology, University Medical Centre Hamburg-Eppendorf, D-20246 Hamburg, Germany; \\ ${ }^{2}$ Institute of Pathology, University Hospital Basel, 4056 Basel, Switzerland; ${ }^{3}$ Department of Gynaecology, \\ Hospital Itzehoe, D-25524 Itzehoe; ${ }^{4}$ Department of Gynaecology, Hospital Pinneberg, D-25421 Pinneberg; \\ ${ }^{5}$ Department of Gynaecology, University Medical Centre Hamburg-Eppendorf, D-20246 Hamburg; \\ ${ }^{6}$ Department of Gynaecology, Hospital Elmshorn, D-25337 Elmshorn; ${ }^{7}$ Institute for Pathology, \\ University of Cologne, D-50937 Cologne, Germany
}

Received November 10, 2015; Accepted February 15, 2016

DOI: $10.3892 / \mathrm{mmr} .2016 .5430$

\begin{abstract}
Angiogenesis is a key process in tumor growth and progression, which is controlled by vascular endothelial growth factors (VEGFs) and their receptors (VEGFRs). In order to better understand the prevalence and prognostic value of VEGFR1 expression in breast cancer, a tissue microarray containing $>2,100$ breast cancer specimens, with clinical follow-up data, was analyzed by immunohistochemistry using an antibody directed against the membrane-bound full-length receptor protein. The results demonstrated that membranous VEGFR1 staining was detected in all (5 of 5) normal breast specimens. In carcinoma specimens, membranous staining was negative in $3.1 \%$, weak in $6.3 \%$, moderate in $10.9 \%$, and strong in $79.7 \%$ of the 1,630 interpretable tissues. Strong staining was significantly associated with estrogen receptor and progesterone receptor expression, but was inversely associated with advanced tumor stage ( $\mathrm{P}=0.0431)$, high Bloom-RichardsonEllis Score for Breast Cancer grade and low Ki67 labeling index (both $\mathrm{P}<0.0001$ ). Cancers with moderate to strong (high) VEGFR1 expression were associated with significantly improved overall survival, as compared with tumors exhibiting negative or weak (low) expression $(\mathrm{P}=0.0015)$. This association was also detected in the subset of nodal-positive cancers $(\mathrm{P}=0.0018)$, and in the subset of 185 patients who had received tamoxifen as the sole therapy $(\mathrm{P}=0.001)$. In conclusion, these
\end{abstract}

Correspondence to: Professor Alexander Quaas, Institute for Pathology, University of Cologne, 62 Kerpener Street, D-50937 Cologne, Germany

E-mail: alexander.quaas@uk-koeln.de

Key words: vascular endothelial growth factor receptor, prognosis, breast cancer, immunohistochemistry data indicated that membrane-bound VEGFR1 is frequently expressed in normal and cancerous breast epithelium. In addition, reduced or lost VEGFR1 expression may serve as a marker for poor prognosis in patients with breast cancer, who might not optimally benefit from endocrine therapy.

\section{Introduction}

Breast cancer is the most common malignancy in women. Despite major improvements in early detection through advanced screening and therapy, 522,000 women succumbed to this disease worldwide in 2012 (1). Angiogenesis is a key feature of tumor cells, which is necessary to overcome the hypoxia that is associated with cancer outgrowth. However, previous therapies targeting vascular development have failed to show a clear survival benefit for patients with breast cancer (2). Therefore, it is hypothesized that improved understanding regarding the role of vascular endothelial growth factors (VEGFs) and their receptors (VEGFRs) may help to improve future therapies.

The VEGF family comprises five structurally related factors: VEGF-A, -B, -C, -D and placenta growth factor, which act as the primary activators of angiogenesis by binding to the following tyrosine kinase receptors: VEGFR1, 2 and 3. The roles of VEGFR2 and VEGFR3 as direct stimulators of angiogenesis (VEGFR2) and lymphangiogenesis (VEGFR3) have been thoroughly characterized; however, the function of VEGFR1 is less clear. The VEGFR1 gene (FLT-1) encodes two proteins: Membrane-bound fibroblast growth factor receptor 1 and a soluble form termed sVEGFR1. Both protein forms have been reported to negatively regulate VEGFR2 via high-affinity binding of VEGFs, which consequently become unavailable for VEGFR2 (3). However, it has previously been suggested that VEGFR1 may indirectly promote tumor cell growth by activating monocytes and macrophages, which invade the tumor and produce VEGFs and cytokines, leading 
to angiogenesis and lymphangiogenesis via activation of VEGFR2 and VEGFR3 (4,5).

Previous studies have analyzed the expression patterns and prognostic significance of VEGFR1 in breast cancer and cancer-associated vascular tissues. Positive associations have been reported between high-level VEGFR1 expression and adverse tumor features, including an increased risk for metastasis and relapse in tumors with strongly VEGFR1-positive endothelial cells (6), as well as shortened survival (7) and positive lymph node stage (8) if tumor cells exhibit strong VEGFR1 staining. Conversely, other studies have reported opposite findings, including absence of lymph node metastases in strongly VEGFR1-positive cancers (9), lack of an association with overall survival (6), or generally infrequent positivity of VEGFR1 in breast cancer cells (10). Similar discrepant findings have also been reported in normal breast epithelial cells, with studies describing either no expression $(10,11)$, or uniformly positive staining (12).

Due to these discordant findings, the present study aimed to analyze an existing large breast cancer tissue microarray, including $>2,000$ breast cancer samples, using an antibody directed specifically against the membrane-bound form of VEGFR1. The results detected an association between reduced membranous expression of VEGFR1 and adverse features of breast cancer.

\section{Materials and methods}

Breast cancer tissue microarray. A breast cancer tissue microarray was used in the present study, which has previously been described in detail (13). Briefly, 2,197 formalin-fixed (neutral-buffered aqueous $4 \%$ solution), paraffin-embedded tumor samples from patients with a median patient age of 62 years (range, 26-101 years) and a median follow-up time of 68 months (range, 1-176 months) were assembled in a tissue microarray format (Table I). One tissue cylinder per case, with a diameter of $0.6 \mathrm{~mm}$, was obtained from representative tumor areas of a 'donor' tissue block using a homemade semiautomatic robotic precision instrument. Histological grade was determined according to the Bloom-RichardsonEllis Score for Breast Cancer (BRE score) (14). Several molecular data used in the present study are available from previously published studies. These include amplification data obtained by fluorescence in situ hybridization (FISH) for human epidermal growth factor (HER2), MYC and cyclin D1 (CCND1), and expression data obtained by immunohistochemistry (IHC) for estrogen receptor (ER), progesterone receptor (PR) and Ki67 (13,15). All tissue samples included in the present study were double-pseudomized leftover samples from routine pathological diagnoses, which can be used for research purposes without informed consent according to local laws ( $\$ 12$ HmbKHG; Hamburg, Germany). Manufacturing and usage of tissue microarrays for research purposes has been approved by the local institutional review board under protocol \#WF-049/09. Control tissue was obtained from tumor patients normal breast tissue.

VEGFR IHC. Standard indirect immunoperoxidase procedures were used for the detection of VEGFR1 (rabbit polyclonal antibody; cat. no. ab2350; 1:450 dilution; Abcam, Cambridge,
UK). Sections were heated in an autoclave at $121^{\circ} \mathrm{C}$ for $10 \mathrm{~min}$ in Tris-EDTA-Citrate buffer ( $\mathrm{pH} 7.8)$. Primary antibody was incubated for $60 \mathrm{~min}$ at $37^{\circ} \mathrm{C}$. Endogenous peroxidase was blocked with Dako S2023 for $10 \mathrm{~min}$ at $20^{\circ} \mathrm{C}$, followed by anti-rabbit peroxidase (Dako real envision detection system K5007; Dako, Glostrup, Denmark) for $30 \mathrm{~min}$ at $37^{\circ} \mathrm{C}$. Diaminobenzidine (Dako) was applied for $10 \mathrm{~min}$ at $20^{\circ} \mathrm{C}$ and sections were counterstained with Mayer's hematoxylin (Sigma-Aldrich). The VEGFR1 staining intensity and the fraction of stained tumor cells were recorded for each tissue specimen (Axiophot Neofluar 20x; Zeiss, Oberkochen, Germany). Staining intensity was estimated using a 4-step scale: 0 , no staining; $1+$, faint intensity; $2+$, moderate intensity; $3+$, strongest intensity. The fraction of stained cells was scored according to the following criteria: Score 0, no stained cells; score $1, \leq 25 \%$ stained cells; score $2, \leq 50 \%$ stained cells; score $3, \leq 75 \%$ stained cells; and score $4,>75 \%$ stained cells. A final IHC result was generated from these scores: Negative, no staining at all; weak, intensity $1+$ in $\leq 70 \%$ of cells, or intensity $2+$ in $\leq 30 \%$ of cells; moderate, intensity $1+$ in $>70 \%$ of cells, intensity $2+$ in $>30 \%$ but $\leq 70 \%$ of cells, or intensity $3+$ in $\leq 30 \%$ of cells; strong, intensity $2+$ in $>70 \%$ of cells, or intensity $3+$ in $>30 \%$ of cells.

Statistical analysis. Pearson's $\chi^{2}$ test and Student's t-test were used to study the relationship between VEGFR1 IHC results and clinicopathological or molecular parameters. The effect of VEGFR1 on survival was assessed by Kaplan-Meier curves and log-rank tests. A Cox proportional-hazards model was used to identify independent factors associated with overall survival. Statistical analysis was performed using JMP version 9.0 statistical software package (SAS Institute Software $\mathrm{GmbH}$, Böblingen, Germany). $\mathrm{P}<0.05$ was considered to indicate a statistically significant difference.

\section{Results}

Technical issues. A total of 567 of 2,197 (25.8\%) tissue specimens were non-informative for VEGFR1 IHC, due to the complete lack of tissue or absence of unequivocal cancer cells.

Association of VEGFRI IHC results with breast cancer phenotype, cell proliferation, and molecular markers. VEGFR1 immunostaining was located in the membrane, and sometimes also the cytoplasm of luminal epithelial cells. Five samples of normal breast epithelium included in the tissue microarray exhibited strong VEGFR1 staining. Cancer cells typically exhibited strong staining compared with the staining intensity observed in the normal breast samples: Staining was strong in $1,299(79.7 \%)$, moderate in $178(10.9 \%)$, weak in $102(6.3 \%)$ and negative in 51 (3.1\%), of the 1,630 interpretable cancers. Representative images of VEGFR1 staining in normal and cancerous breast tissues are presented in Fig. 1. VEGFR1 staining levels were comparable (70-90\% with strong staining) in the majority of different histological subtypes, apart from medullary cancers, which exhibited a significantly lower fraction of strongly VEGFR1-positive tumors (50\%, P<0.0002), as compared with carcinoma of no special type (NST). In addition, VEGFR1 staining was inversely associated with tumor stage $(\mathrm{P}=0.0431)$ and $\mathrm{BRE}$ grade $(\mathrm{P}<0.0001)$, although 
Table I. Association between VEGFR1 IHC results and breast cancer phenotype, ER and PR status, HER2, MYC and CCND1 amplification, and triple negative category.

\begin{tabular}{|c|c|c|c|c|c|c|}
\hline \multirow[b]{2}{*}{ Parameters } & \multirow[b]{2}{*}{ Interpretable (n) } & \multicolumn{4}{|c|}{ VEGFR1 IHC result (\%) } & \multirow[b]{2}{*}{ P-value } \\
\hline & & Negative & Weak & Moderate & Strong & \\
\hline All types of cancer & 1,630 & 3.1 & 6.3 & 10.9 & 79.7 & \\
\hline \multicolumn{7}{|l|}{ Histology } \\
\hline No special type & 1,146 & 3.1 & 6.2 & 11.6 & 79.1 & \\
\hline Lobular carcinoma & 227 & 2.2 & 3.5 & 6.2 & 88.1 & \\
\hline Cribriform carcinoma & 48 & 0.0 & 6.3 & 6.3 & 87.5 & \\
\hline Medullary carcinoma & 38 & 13.2 & 21.1 & 15.8 & 50.0 & $0.0002^{\mathrm{b}}$ \\
\hline Tubular carcinoma & 40 & 0.0 & 2.5 & 7.5 & 90.0 & \\
\hline Papillary carcinoma & 24 & 4.2 & 4.2 & 16.7 & 75.0 & \\
\hline Mucinous carcinoma & 46 & 2.2 & 10.9 & 10.9 & 76.1 & \\
\hline Other rare types ${ }^{\mathrm{a}}$ & 61 & 4.9 & 8.2 & 16.4 & 70.5 & \\
\hline pT stage & & & & & & 0.0431 \\
\hline pT1 & 540 & 1.5 & 5.2 & 10.0 & 83.3 & \\
\hline pT2 & 784 & 3.7 & 7.1 & 12.1 & 77.0 & \\
\hline pT3 & 99 & 7.1 & 4.0 & 8.1 & 80.8 & \\
\hline pT4 & 198 & 3.5 & 6.6 & 9.6 & 80.3 & \\
\hline BRE grade & & & & & & $<0.0001$ \\
\hline Grade 1 & 384 & 2.9 & 3.4 & 6.5 & 87.2 & \\
\hline Grade 2 & 627 & 1.9 & 5.6 & 9.7 & 82.8 & \\
\hline Grade 3 & 506 & 5.1 & 9.7 & 14.2 & 70.9 & \\
\hline Nodal stage & & & & & & 0.073 \\
\hline $\mathrm{pNO}$ & 671 & 3.4 & 7.0 & 12.1 & 77.5 & \\
\hline $\mathrm{pN} 1$ & 584 & 2.2 & 5.8 & 11.0 & 81.0 & \\
\hline $\mathrm{pN} 2$ & 93 & 7.5 & 11.8 & 10.8 & 69.9 & \\
\hline ER/PR status & & & & & & $<0.0001$ \\
\hline Negative & 313 & 5.1 & 11.8 & 15.7 & 67.4 & \\
\hline Positive & 1,156 & 2.6 & 4.6 & 10.0 & 82.8 & \\
\hline HER2 FISH & & & & & & 0.0745 \\
\hline No amplification & 1,051 & 3.1 & 5.8 & 10.4 & 80.7 & \\
\hline Amplification & 227 & 0.9 & 3.5 & 10.6 & 85.0 & \\
\hline Triple negative & & & & & & $<0.0001$ \\
\hline No & 1,021 & 2.0 & 4.0 & 9.7 & 84.3 & \\
\hline Yes & 159 & 8.2 & 13.2 & 17.0 & 61.6 & \\
\hline CCND1 FISH & & & & & & 0.396 \\
\hline No amplification & 1,129 & 2.6 & 5.1 & 10.9 & 81.4 & \\
\hline Amplification & 281 & 2.1 & 7.8 & 10.3 & 79.7 & \\
\hline MYC FISH & & & & & & 0.1374 \\
\hline No amplification & 1,146 & 2.9 & 5.8 & 10.5 & 80.9 & \\
\hline Amplification & 66 & 6.1 & 6.1 & 18.2 & 69.7 & \\
\hline
\end{tabular}

VEGFR1, vascular endothelial growth factor receptor 1; IHC, immunohistochemistry; pT, primary tumor; ER, estrogen receptor; PR, proges-

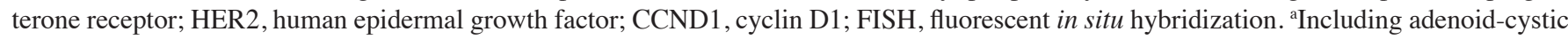
carcinoma, apocrine carcinoma, atypical medullary carcinoma, carcinosarcoma, clear cell carcinoma, histiocytic carcinoma, lipid-rich carcinoma, lipid-rich or histiocytoic carcinoma, metaplastic carcinoma, neuroendocrine carcinoma, signet ring carcinoma, and small cell carcinoma. ${ }^{\mathrm{b}}$ Medullary vs. carcinoma of no special type.

the difference in numbers was only small. Staining levels were unrelated to the presence of lymph node metastases.
Cell proliferation was previously determined immunohistochemically using the Ki67 labeling index (LI) (13). An inverse 
A

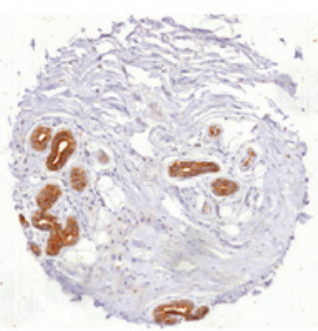

C

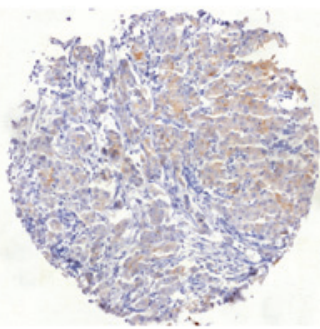

$\mathbf{E}$

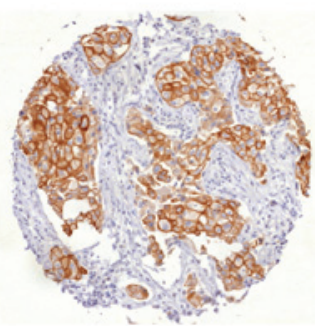

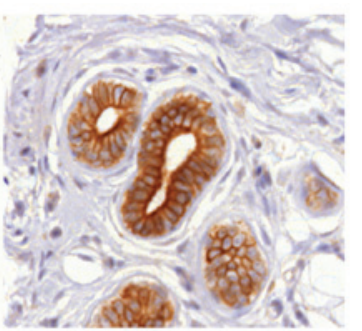
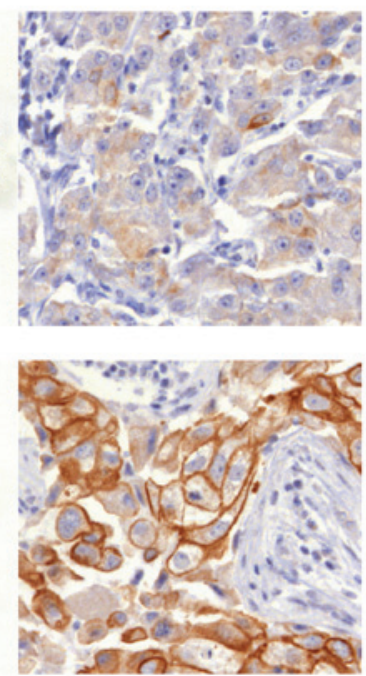

B
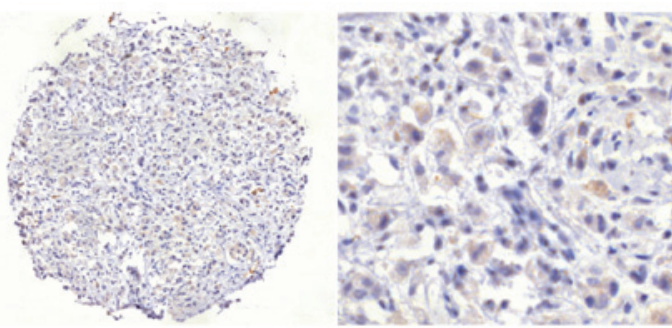

D
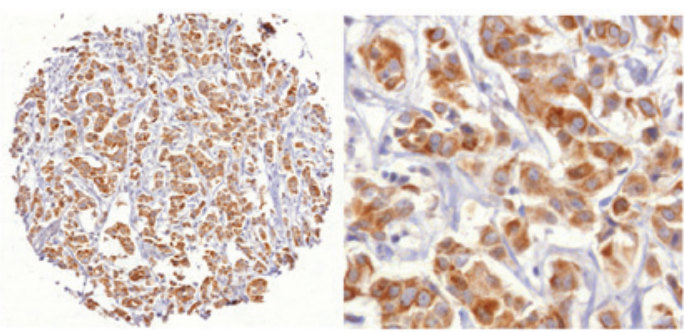

$\mathbf{F}$

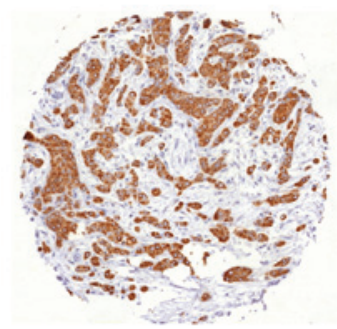

Figure 1. Representative images of vascular endothelial growth factor receptor 1 immunostaining. (A) Normal breast tissue, (B-F) breast cancer tissue with (B) negative, (C) weak, and (D and E) moderate to strong staining at 10x and 40x magnification. Staining localization was either (D) mainly cytoplasmic,

(E) mainly membranous, (F) or both cytoplasmic and membranous.

association was detected between VEGFR1 staining and cell proliferation: The average Ki67LI increased from $26.5 \%$ in 1,135 cancer specimens with strong VEGFR1 staining to $33.1 \%$ in 46 tumors lacking detectable VEGFR1 staining $(\mathrm{P}<0.0001$; Fig. 2). Strong VEGFR1 immunostaining was also associated with positive ER and PR status and the triple negative category (all $\mathrm{P}<0.0001$ ); however, VEGFR staining was unrelated to amplifications in HER2, CCND1 or MYC. The results are summarized in Table I. A multivariate analysis of overall survival demonstrated that VEGFR1 staining had non-significant impact on hazard ratio (Table II).

Association with patient survival and response to tamoxifen treatment. To exclude a potential influence of the histological subtype on patient prognosis, survival analysis was limited to the largest subset of 1,144 carcinomas of NST with interpretable VEGFR1 IHC data. Since tumors with moderate or strong staining exhibited improved overall survival compared with tumors with negative or weak staining ( $\mathrm{P}=0.0054$; Fig. 3A), all NST specimens were grouped into subsets with low (i.e. negative or weak) or high (i.e. moderate or strong) staining for further survival analyses. According to these groups, tumors with high VEGFR1 staining exhibited superior overall survival in all subsets of NST $(\mathrm{P}=0.0015$; Fig. 3B). This association was also true for subsets of nodal-negative NST (pN0, $\mathrm{P}=0.0256$; Fig. 3C) and nodal-positive NST (pN1-2, P=0.0018; Fig. 3D). Additional analysis in a subset of 185 patients with breast cancer who had received tamoxifen monotherapy revealed a significant association between high levels of VEGFR1 and prolonged survival after treatment $(\mathrm{P}=0.0010$; Fig. 3E).

\section{Ki67 LI}

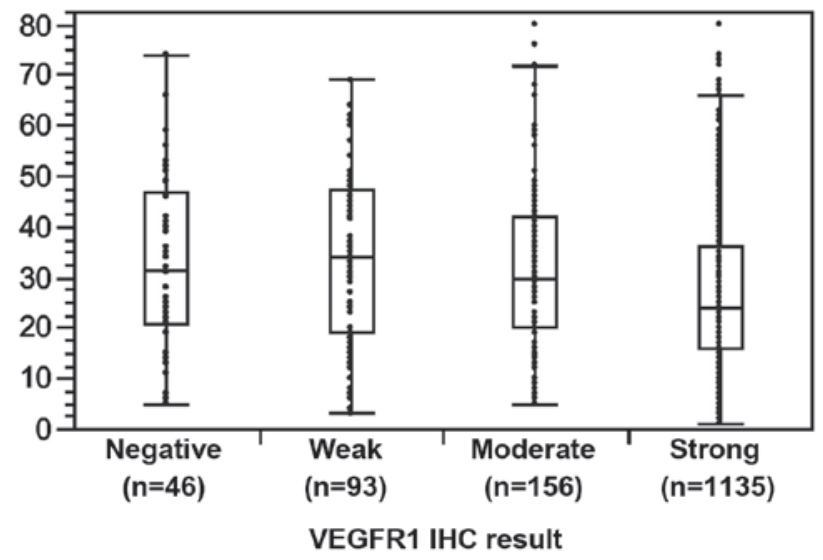

Figure 2. Association between VEGFR1) immunostaining levels and cell proliferation, as determined using the Ki67 labeling index (LI) $(\mathrm{P}<0.0001)$ Box plots show 1st, 2nd (median) and 3rd quartile. Whiskers indicate 3rd quartile $+1.5 x$ interquartile range or 1 st quartile $-1.5 x$ interquartile range. VEGFR1, vascular endothelial growth factor receptor 1; IHC, immunohistochemistry.

\section{Discussion}

The present study successfully analyzed $>1,600$ breast cancer specimens using an antibody directed against membrane-bound VEGFR1. The results suggested that high-level immunostaining of VEGFR1 is a common feature of normal and cancerous breast epithelial cells, and that lost 
Table II. Multivariate analysis of overall survival in 824 patients, including tumor stage, BRE grade, nodal stage, ER and PR status, HER2 amplification, triple negative category, Ki67 labeling index and VEGFR1 staining.

\begin{tabular}{|c|c|c|c|}
\hline Clinicopathological parameter & Hazard ratio & 95\% Confidence interval & P-value \\
\hline \multicolumn{4}{|l|}{ pT stage } \\
\hline pT2 vs. pT1 & 1.4 & $1.02-2.04$ & 0.0357 \\
\hline pT3 vs. pT2 & 1.0 & $0.61-1.46$ & 0.8753 \\
\hline pT4 vs. pT3 & 1.7 & $1.08-2.80$ & 0.021 \\
\hline \multicolumn{4}{|l|}{ BRE grade } \\
\hline Grade 2 vs. grade 1 & 1.5 & $0.97-2.29$ & 0.0707 \\
\hline Grade 3 vs. grade 1 & 1.9 & $1.38-2.8$ & $<0.0001$ \\
\hline \multicolumn{4}{|l|}{ Nodal stage } \\
\hline pN1 vs. pN0 & 2.7 & $2.03-3.73$ & $<0.0001$ \\
\hline pN2 vs. pN1 & 1.9 & $1.34-2.8$ & 0.0007 \\
\hline \multicolumn{4}{|l|}{ ER status } \\
\hline Negative vs. positive & 1.6 & $0.25-5.12$ & 0.5677 \\
\hline \multicolumn{4}{|l|}{ PR status } \\
\hline Negative vs. positive & 1.5 & $1.07-2.02$ & 0.018 \\
\hline \multicolumn{4}{|l|}{ ER/PR status } \\
\hline Negative vs. positive & 0.4 & $0.1-2.38$ & 0.2485 \\
\hline \multicolumn{4}{|l|}{ HER2 FISH } \\
\hline No vs. amplification & 0.5 & $0.36-0.78$ & 0.0021 \\
\hline \multicolumn{4}{|l|}{ Triple negative } \\
\hline Yes vs. no & 2.7 & $1.51-4.92$ & 0.0009 \\
\hline \multicolumn{4}{|l|}{ Ki67 labeling index } \\
\hline Per unit change & 1.0 & $0.99-1.01$ & 0.4404 \\
\hline \multicolumn{4}{|l|}{ VEGFR1 } \\
\hline Weak vs. negative & 0.9 & $0.47-1.93$ & 0.843 \\
\hline Moderate vs. weak & 0.6 & $0.33-1.08$ & 0.087 \\
\hline High vs. moderate & 1.2 & $0.82-1.92$ & 0.3337 \\
\hline
\end{tabular}

pT, primary tumor; ER, estrogen receptor; PR, progesterone receptor; HER2, human epidermal growth factor; FISH, fluorescent in situ hybridization; VEGFR1, vascular endothelial growth factor receptor 1.

or reduced expression of VEGFR1 is associated with tumor progression, rapid cell proliferation and shortened survival.

All normal breast tissues (5/5) and $90 \%$ of cancer tissues exhibited moderate to strong VEGFR1 immunostaining in the present study, indicating that high levels of VEGFR1 represent a physiological situation. These data thus corroborate the hypothesis that full-length VEGFR1 physiologically regulates VEGFR2 activity by trapping free VEGF $(3,16)$. In addition, these results are consistent with the findings of a previous study, which suggested that VEGFR1 expression is indicative of better prognosis in breast cancer (9). Based on the known function of VEGFR2 as an activator of cell growth $(17,18)$, the adverse features of breast cancers with low-level VEGFR1 expression may be a consequence of unregulated VEGFR2 activation in the absence of sufficient levels of VEGFR1.

The high rate of cancers with high-level VEGFR1 expression in the present study is consistent with the results of a recent study reporting $100 \%$ positivity in 25 normal breast samples and $90 \%$ positivity in 96 invasive breast cancer samples (12). Notably, in the previous study, the same antibody was used as in the present analysis. According to the manufacturer's datasheet, this particular polyclonal antibody (ab2350; Abcam) detects a $180 \mathrm{kD}$ protein sequence, which is not present in sVEGFR, and does also not detect the phosphorylated form. Other studies using different antibodies have reported largely variable results, including complete lack of staining in normal breast epithelium (10), and a broad range of positivity in cancer cells ranging from $16-91 \%(7,9,10,19)$. Furthermore, compared with the findings of the present study, several of these studies also detected associations between strong VEGFR1 staining and adverse features of breast cancer, including early recurrence, reduced overall survival and metastasis (6-8). Such discrepant findings are most likely attributed to the different antibodies used in these studies. Notably, the majority of studies described cytoplasmic staining (6-8), which is unexpected given that full-length VEGFR1 is a membrane-bound receptor, and that at least some membranous staining would be expected. However, high homology exists between the full-length membranous VEGFR1, sVEGFR1 lacking the transmembrane and intracellular domains, and the five 

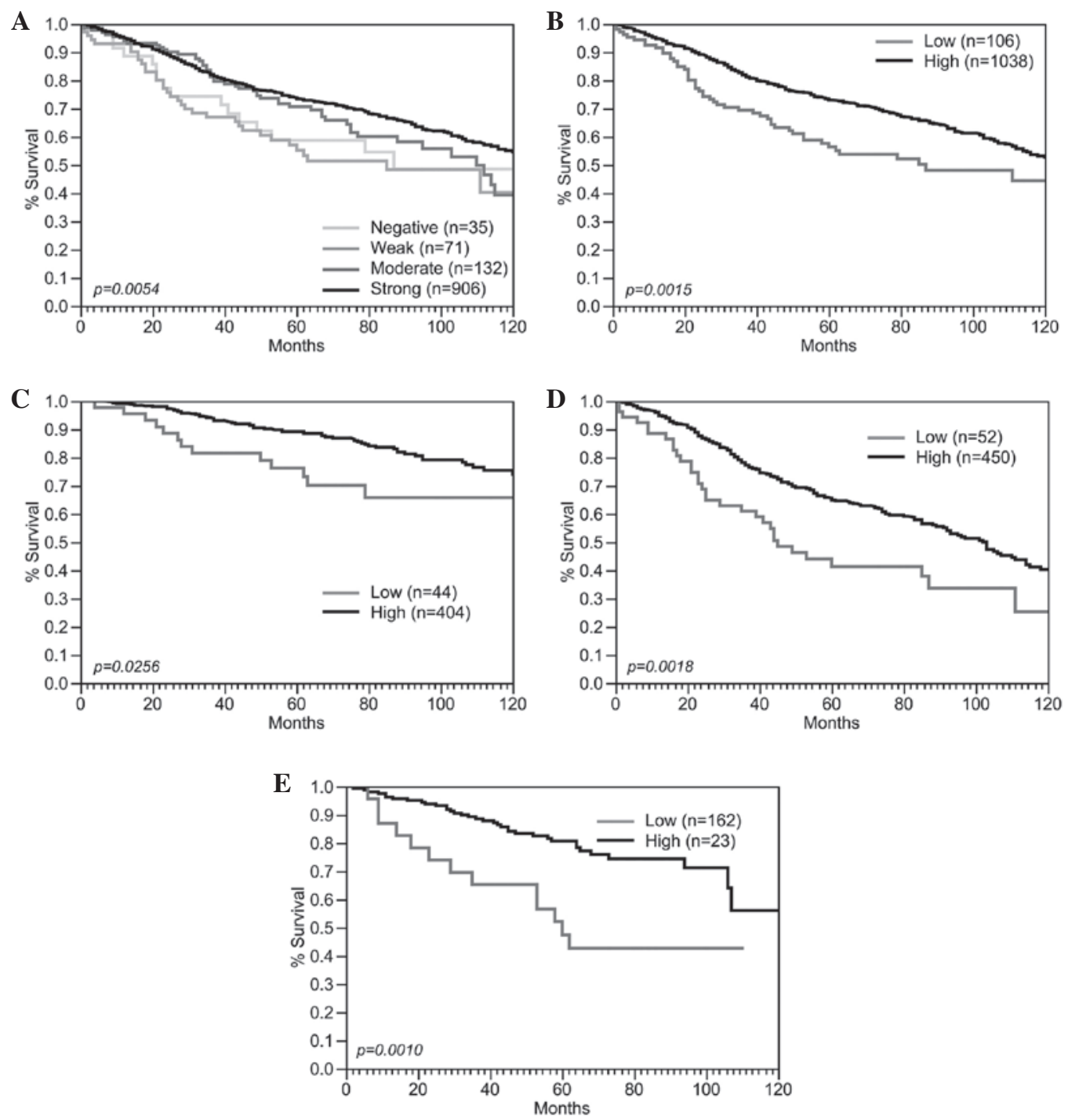

Figure 3. Prognostic significance of vascular endothelial growth factor receptor 1 staining in (A) all cancers of no special type (NST), (B) in all NST cancers grouped according to low (negative and weak) and high (moderate and strong) staining, (C) in the subset of nodal-negative NST cancers, (D) in the subset of nodal-positive NST cancers, and (E) in the subset of 185 patients with breast cancer that received tamoxifen monotherapy.

different intracellular forms (iVEGFR1, possessing only one or more of the intracellular domains) that have recently been described (20). Therefore, it appears possible that some antibodies may cross-react with several forms of VEGFR1. This would provide an explanation for some of the discrepant findings, in particular since numerous studies have demonstrated that sVEGFR1 and iVEGFR1 have opposite implications for tumor biology and patient prognosis $(21,22)$.

In the present study, low levels of VEGFR1 expression were associated with reduced ER and PR positivity in all cancer specimens, as well as shortened survival in the subset of ER-positive patients receiving endocrine (tamoxifen) therapy. These results provide additional support for the concept that VEGFR1 acts as a negative regulator of VEGFR2 signaling, since several studies have reported that activation of VEGFR2 is associated with high tumor stage and grade, metastatic growth, negative ER status and early recurrence in patients with breast cancer following tamoxifen therapy $(17,23,24)$. Furthermore, the findings of the present study suggest that VEGFR1, possibly in combination with
VEGFR2, may be a suitable marker to stratify patients for endocrine therapy.

In 2008, the Food and Drug Administration approved the VEGF neutralizing antibody bevacizumab for the treatment of advanced and metastatic breast cancer. However, subsequent large clinical phase III trials (e.g. E2100, AVADO, RIBBON-1 and -2) (25-27) have failed to detect a clear survival benefit, resulting in withdrawal of the approval in 2011. The reasons for the lack of a therapeutic benefit remain poorly understood, although the pivotal role of angiogenesis in cancer growth is undisputed (28). Since $90 \%$ of cancers in the present study, including 70-80\% high grade, advanced and metastatic tumors, exhibited high-level VEGFR1 staining, it seems obvious that the vast majority of breast cancers are capable of regulating growth signaling via an intact VEGF/VEGFR1 loop. It would be interesting to study the effects of VEGF inhibitors in breast cancers with various levels of VEGFR1. Theoretically, it may be speculated that VEGF inhibition could be more effective in tumor cells lacking VEGFR1 expression, than in those with physiologically high protein levels, and that VEGFR1 
levels could be of potential value in selecting patients for anti-angiogenic therapies.

A tissue microarray with a single $0.6 \mathrm{~mm}$ spot per cancer was used in the present study. A limitation of the present study is that this approach is not suitable for the detection of possible intratumoral heterogeneity of VEGFR expression. Therefore, it is possible that some cancers with heterogenous VEGFR expression were overlooked in the present analysis. It has previously been suggested that analysis of multiple spots per tumor may increase the representativeness of microarray studies $(29,30)$. However, this approach bears the disadvantage that not all tissue spots of one cancer are interpretable. Given that the likelihood of finding a positive result increases with the number of interpretable tissue spots, analysis of various amounts of cancer spots per patient may introduce a statistical bias to the analysis (31). Our previous study demonstrated that microarrays consisting of a single spot per cancer are superior for detecting clinically relevant associations between molecular markers and breast cancer phenotype (32). In addition, previous tissue microarray studies using a single spot per tumor have been able to reproduce known associations between molecular markers and cancer phenotype, or patient prognosis in breast cancer $(13,32,33)$.

A limitation of the present study is that only one (VEGFR1) of many angiogenic molecules, including VEGFR2, VEGFR3, neuropilin (NRP)1 or NRP2, was analyzed (34). Given the complex biological interactions of these receptors and their corresponding growth factors it would be interesting to study their co-expression patterns, provided that antibodies suitable for formalin-fixed tissues become available, in order to obtain a comprehensive picture of angiogenic factors in breast cancer.

In conclusion, the results of the present study suggested that reduced or lost expression of full-length and membrane-bound VEGFR1 identifies a small but clinically relevant subset of breast cancers that are characterized by adverse tumor features and shortened survival, which may not respond optimally to endocrine therapy. Furthermore, the choice of antibody may have a serious impact on the outcome of VEGFR1 expression analyses.

\section{Acknowledgements}

The authors would like to thank Mrs Christina Koop, Mrs Janett Lütgens, Mrs Sünje Seekamp and Mrs Inge Brandt (Institute of Pathology) for their excellent technical support.

\section{References}

1. International Agency for Research on Cancer (IARC): GLOBOCAN 2012: Estimated cancer incidence, mortality and prevalence worldwide in 2012. IARC fact sheets. http://globocan. iarc.fr/Pages/fact_sheets_cancer.aspx. Accessed May 27, 2016.

2. Rossari JR, Metzger-Filho O, Paesmans M, Saini KS, Gennari A, de Azambuja E and Piccart-Gebhart M: Bevacizumab and breast cancer: A meta-analysis of first-line phase III studies and a critical reappraisal of available evidence. J Oncol 2012: 417673, 2012.

3. Shibuya M: Vascular endothelial growth factor and its receptor system: Physiological functions in angiogenesis and pathological roles in various diseases. J Biochem 153: 13-19, 2013.

4. Lin EY, Li JF, Gnatovskiy L, Deng Y, Zhu L, Grzesik DA, Qian H, Xue XN and Pollard JW: Macrophages regulate the angiogenic switch in a mouse model of breast cancer. Cancer Res 66: 11238-11246, 2006.
5. Murakami M, Zheng Y, Hirashima M, Suda T, Morita Y, Ooehara J, Ema H, Fong GH and Shibuya M: VEGFR1 tyrosine kinase signaling promotes lymphangiogenesis as well as angiogenesis indirectly via macrophage recruitment. Arterioscler Thromb Vasc Biol 28: 658-664, 2008.

6. Dales JP, Garcia S, Carpentier S, Andrac L, Ramuz O, Lavaut MN, Allasia C, Bonnier P and Taranger-Charpin C: Prediction of metastasis risk (11 year follow-up) using VEGF-R1, VEGF-R2, Tie-2/Tek and CD105 expression in breast cancer $(\mathrm{n}=905)$. Br J Cancer 90: 1216-1221, 2004.

7. Mylona E, Alexandrou P, Giannopoulou I, Liapis G, Sofia M, Keramopoulos A and Nakopoulou L: The prognostic value of vascular endothelial growth factors (VEGFs)-A and -B and their receptor, VEGFR-1, in invasive breast carcinoma. Gynecol Oncol 104: 557-563, 2007.

8. Ning Q, Liu C, Hou L, Meng M, Zhang X, Luo M, Shao S, Zuo X and Zhao X: Vascular endothelial growth factor receptor-1 activation promotes migration and invasion of breast cancer cells through epithelial-mesenchymal transition. PLoS One 8: e65217, 2013.

9. Schmidt M, Voelker HU, Kapp M, Dietl J and Kammerer U: Expression of VEGFR-1 (Flt-1) in breast cancer is associated with VEGF expression and with node-negative tumour stage. Anticancer Res 28: 1719-1724, 2008.

10. Wülfing P, Kersting C, Buerger H, Mattsson B, Mesters R, Gustmann C, Hinrichs B, Tio J, Böcker W and Kiesel L: Expression patterns of angiogenic and lymphangiogenic factors in ductal breast carcinoma in situ. Br J Cancer 92: 1720-1728, 2005.

11. Brown LF, Guidi AJ, Schnitt SJ, Van De Water L, Iruela-Arispe ML, Yeo TK, Tognazzi K and Dvorak HF: Vascular stroma formation in carcinoma in situ, invasive carcinoma, and metastatic carcinoma of the breast. Clin Cancer Res 5: 1041-1056, 1999.

12. Arias-Pulido H, Chaher N, Gong Y, Qualls C, Vargas J and Royce M: Tumor stromal vascular endothelial growth factor A is predictive of poor outcome in inflammatory breast cancer. BMC Cancer 12: 298, 2012.

13. Ruiz C, Seibt S, Al Kuraya K, Siraj AK, Mirlacher M, Schraml P, Maurer R, Spichtin H, Torhorst J, Popovska S, et al: Tissue microarrays for comparing molecular features with proliferation activity in breast cancer. Int J Cancer 118: 2190-2194, 2006.

14. Elston CW and Ellis IO: Pathological prognostic factors in breast cancer. I. The value of histological grade in breast cancer: Experience from a large study with long-term follow-up. Histopathology 19: 403-410, 1991

15. Al-Kuraya K, Schraml P, Torhorst J, Tapia C, Zaharieva B, Novotny H, Spichtin H, Maurer R, Mirlacher M, Köchli O, et al: Prognostic relevance of gene amplifications and coamplifications in breast cancer. Cancer Res 64: 8534-8540, 2004.

16. Hiratsuka S, Minowa O, Kuno J, Noda T and Shibuya M: Flt-1 lacking the tyrosine kinase domain is sufficient for normal development and angiogenesis in mice. Proc Natl Acad Sci USA 95: 9349-9354, 1998

17. Linderholm BK, Hellborg H, Johansson U, Skoog L and Lehtiö J: Vascular endothelial growth factor receptor 2 and downstream p38 mitogen-activated protein kinase are possible candidate markers of intrinsic resistance to adjuvant endocrine treatment in steroid receptor positive breast cancer. Breast Cancer Res Treat 125: 457-465, 2011.

18. Jin J, Yuan F, Shen MQ, Feng YF and He QL: Vascular endothelial growth factor regulates primate choroid-retinal endothelial cell proliferation and tube formation through PI3K/Akt and MEK/ERK dependent signaling. Mol Cell Biochem 381: 267-272, 2013.

19. Paradiso A, Mangia A, Chiriatti A, Tommasi S, Zito A, Latorre A, Schittulli F and Lorusso V: Biomarkers predictive for clinical efficacy of taxol-based chemotherapy in advanced breast cancer. Ann Oncol 16 (Suppl 4): iv14-iv19, 2005.

20. Mezquita B, Mezquita J, Pau M and Mezquita C: A novel intracellular isoform of VEGFR-1 activates Src and promotes cell invasion in MDA-MB-231 breast cancer cells. J Cell Biochem 110: 732-742, 2010.

21. Toi M, Bando H, Ogawa T, Muta M, Hornig $\mathrm{C}$ and Weich HA: Significance of vascular endothelial growth factor (VEGF)/soluble VEGF receptor-1 relationship in breast cancer. Int J Cancer 98: 14-18, 2002.

22. Bando H, Weich HA, Brokelmann M, Horiguchi S, Funata N, Ogawa $\mathrm{T}$ and Toi $\mathrm{M}$ : Association between intratumoral free and total VEGF, soluble VEGFR-1, VEGFR-2 and prognosis in breast cancer. Br J Cancer 92: 553-561, 2005. 
23. Ryden L, Jirström K, Bendahl PO, Fernö M, Nordenskjöld B, Stål O, Thorstenson S, Jönsson PE and Landberg G: Tumor-specific expression of vascular endothelial growth factor receptor 2 but not vascular endothelial growth factor or human epidermal growth factor receptor 2 is associated with impaired response to adjuvant tamoxifen in premenopausal breast cancer. J Clin Oncol 23: 4695-4704, 2005.

24. Johansson I, Aaltonen KE, Ebbesson A, Grabau D, Wigerup C, Hedenfalk I and Rydén L: Increased gene copy number of KIT and VEGFR2 at 4q12 in primary breast cancer is related to an aggressive phenotype and impaired prognosis. Genes Chromosomes Cancer 51: 375-383, 2012.

25. Gray R, Bhattacharya S, Bowden C, Miller K and Comis RL: Independent review of E2100: a phase III trial of bevacizumab plus paclitaxel versus paclitaxel in women with metastatic breast cancer. J Clin Oncol 27: 4966-4972, 2009.

26. Miles DW, de Haas SL, Dirix LY, et al: Biomarker results from the AVADO phase 3 trial of first-line bevacizumab plus docetaxel for HER2-negative metastatic breast cancer. Br J Cancer108: 1052-1060, 2013.

27. Robert NJ, Diéras V, Glaspy J, et al: RIBBON-1: randomized, double-blind, placebo-controlled, phase III trial of chemotherapy with or without bevacizumab for first-line treatment of human epidermal growth factor receptor 2-negative, locally recurrent or metastatic breast cancer. J Clin Oncol29: 1252-1260, 2011.
28. Folkman J: Angiogenesis in cancer, vascular, rheumatoid and other disease. Nat Med 1: 27-31, 1995.

29. Camp RL, Charette LA and Rimm DL: Validation of tissue microarray technology in breast carcinoma. Lab Invest 80: 1943-1949, 2000.

30. Zhang D, Salto-Tellez M, Putti TC, Do E and Koay ES: Reliability of tissue microarrays in detecting protein expression and gene amplification in breast cancer. Mod Pathol 79-84, 2003.

31. Sauter G: Representativity of TMA Studies. Methods Mol Biol 664: 27-35, 2010

32. Torhorst J, Bucher C, Kononen J, Haas P, Zuber M, Köchli OR, Mross F, Dieterich H, Moch H, Mihatsch M, et al: Tissue microarrays for rapid linking of molecular changes to clinical endpoints. Am J Pathol 159: 2249-2256, 2001.

33. Barlund M, Forozan F, Kononen J, Bubendorf L, Chen Y, Bittner ML, Torhorst J, Haas P, Bucher C, Sauter G, et al: Detecting activation of ribosomal protein S6 kinase by complementary DNA and tissue microarray analysis. J Natl Cancer Inst 92: 1252-1259, 2000.

34. Goel HL and Mercurio AM: VEGF targets the tumour cell. Nat Rev Cancer 13: 871-882, 2013. 